\title{
THEODOR W. ADORNO: IMAGENS DO FEMININO NAS MINIMA MORALIA
}

\section{THEODOR W. ADORNO: FEMININE IMAGES IN MINIMA MORALIA}

\author{
FRANCIELE BETE PETRY \\ (Universidade Federal de Santa Catarina, Brasil)
}

\begin{abstract}
RESUMO
O texto pretende explorar a temática das imagens do feminino nas Minima Moralia: reflexões a partir da vida danificada de Theodor W. Adorno. Nesta obra, está presente uma crítica à forma como a racionalidade instrumental desenvolveu-se na sociedade, tendo como consequência a danificação da subjetividade. Também a esfera particular da vida foi afetada, sendo marcada pela violência, dominação e falsidade. Nesse sentido, a crítica feita por Adorno mostra-se instigante para se pensar as imagens associadas às mulheres na sociedade, à identidade e subjetividade femininas, construídas dentro de uma sociedade patriarcal. Contudo, a reflexão adorniana não pode ser reduzida a uma questão de gênero, pois a violência não é marca exclusiva da repressão feminina, antes, uma qualidade inerente à sociedade capitalista dentro da qual a emancipação, seja ela feminina ou não, encontra obstáculos para sua realização.

Palavras-chave: Adorno. Racionalidade instrumental. Feminino. Crítica dialética.
\end{abstract}

\begin{abstract}
The paper aims at discussing the theme of the feminine images in Theodor W. Adorno's work Minima Moralia: reflections on a damaged life. In this text, there is a criticism to the way in which instrumental rationality has developed into capitalist society, having as consequence the lost of subjectivity. Even private life was influenced by violence, domination, repression and falsity. In this sense, Adorno's critique can be interesting for the reflection on the images socially related to women, and on feminine identity and subjectivity, which are built into a patriarchal society. However, Adorno's position is not to be reduced to a reflection on gender, because violence is not only related to feminine repression, but it is an inherent characteristic of capitalist society, where the possibility of emancipation, feminine or not, cannot be easily achieved.
\end{abstract}

Keywords: Adorno. Instrumental rationality. Feminine. Dialectical critique.

\section{Introdução}

A crítica de Theodor W. Adorno, desenvolvida na obra Minima Moralia: reflexões a partir da vida danificada, é uma denúncia severa de como os mecanismos de dominação se estendem para aspectos da vida muitas vezes julgados como invioláveis. São aquelas esferas que pareceriam ainda estar isoladas de interesse e falsidade, mas que sob uma reflexão mais profunda, se revelam instâncias de dominação e opressão mascaradas. A obra, escrita entre os anos de 1944 e 1947 sob a forma de aforismos, que embora geralmente curtos são suficientemente tensos para provocar uma reflexão dolorosa, se dirige, como o próprio título 
diz, para a vida danificada, fragmentada em decorrência do predomínio de uma racionalidade que se volta contra os seres humanos e os coloca em uma posição de constante dominação, disfarçada por um véu que oculta o preço pago pelo sujeito a fim de sobreviver em uma sociedade reificada em suas mais diversas particularidades.

Falar sobre as mulheres, nesse contexto, é uma exigência da própria crítica proposta pelo livro, que não se abstém de identificar no seio de uma sociedade decadente formas sutis que mascaram a violência sob a qual a imagem do feminino surge. $O$ tratamento peculiar que a obra oferece ao tema reside no fato de que sua crítica não aposta em uma reivindicação de qualquer qualidade que pertença aos homens e é negada às mulheres, mas sim na dissolução de um pensamento que está presente na sociedade e faz de "vítimas" tanto as mulheres quanto aqueles que são seus "carrascos" e que, por isso mesmo, também precisam ser livres para que o todo se liberte. É por isso que ao se tratar da imagem do feminino faz-se necessário uma reflexão que se debruce sobre todas as relações em que tal representação apareça, seja nas relações entre homens e mulheres, seja na do indivíduo com a sociedade. A forma com que Adorno trata o tema se entrelaça com sua crítica à racionalidade, a qual não permite isolar a opressão vivida pelas mulheres de uma violência mais geral que acomete a sociedade como um todo.

A denúncia sobre a opressão feminina exige, nesse sentido, um olhar apurado sobre as várias dimensões que compõem a realidade. Tal olhar não deve ser direto, mas como que dirigido para o avesso, para aquilo que apesar de compor o visível, o aparente, é na verdade o seu contrário, o seu negativo e que não deve ser descartado sob o risco de se tomar a realidade parcialmente. Como diz Adorno no prefácio da obra, "o olhar lançado à vida transformou-se em ideologia, que tenta nos iludir escondendo o fato de que não há mais vida”. ${ }^{1}$

\section{A crítica à ideia de "feminilidade"}

Embora Adorno seja criticado por assumir em seu texto uma perspectiva heterossexual masculina, ${ }^{2}$ sua leitura do modo como a imagem do feminino é construída na sociedade ultrapassa os limites de uma abordagem de gênero, já que se localiza no contexto de uma crítica à racionalidade subjacente aos modos em que a dominação se manifesta. Claramente, as mulheres se encontram em uma posição em que tal opressão é mais evidente, mas a crítica de Adorno mostra que também as representações do masculino obedecem ao imperativo de uma racionalidade de caráter instrumental. Como diz ele, "o caráter feminino e o ideal de 
feminilidade segundo o qual ele é moldado são produtos da sociedade masculina. A imagem da natureza não deformada emerge apenas com a deformação como o seu contrário". ${ }^{3}$ Aqui Adorno parte da tese desenvolvida em conjunto com Horkheimer na Dialética do esclarecimento, segundo a qual a racionalidade instrumental, utilizada no domínio da natureza externa, também é constituinte da formação da própria subjetividade, manifestando-se, assim, como domínio da natureza interna. Tal racionalidade, embora apareça em sua forma mais elaborada no mundo moderno, acompanha o desenvolvimento da civilização desde seus primórdios, sempre associada à tentativa dos seres humanos de se afirmar frente à natureza por meio do pensamento esclarecedor. Nesse contexto, Adorno situa a construção da imagem do feminino em sua relação com aquilo que para aquela racionalidade se coloca como "natural" e que, portanto, deve ser dominado pela razão. Esta, contudo, se associa à imagem masculina, como símbolo de força e dominação. Dessa forma, quando a imagem do feminino se torna sinônimo daquilo que é "puro", "natural”, essas representações assumem o caráter de justificação para a opressão exercida sobre as mulheres no interior de uma sociedade patriarcal, em que o homem assume o papel de senhor sobre a natureza. "Natural" não é, por isso, o âmbito da ausência de poder, mas sim de sua privação, o que faz da representação feminina o inverso da masculina, não na forma de uma oposição direta, mas a partir de um princípio de dominação. Nesse sentido é que Adorno afirma: "quando pretende ser humana, a sociedade masculina cultiva de maneira soberana nas mulheres seu próprio corretivo, mostrando-se na ação de limitar como um senhor implacável. O caráter feminino é como uma cópia calcada no positivo da dominação, e é por isso tão mau quanto esta última". 4

A crítica de Adorno à imagem do feminino, portanto, é duplamente negativa: primeiro, porque reconhece que tal imagem existe a partir de uma perspectiva masculina e de dominação; segundo, porque a ela não se faria justiça concedendo-lhe o poder que na sociedade é associado aos homens, já que também este é avaliado negativamente. Assim, se houver alguma forma de liberação feminina, ela passa pela superação de todas as formas em que a violência e a dominação se apresentam e exige a abolição da distinção entre feminino e masculino em favor da perspectiva do "humano". O pensamento adorniano, aqui, deve seu teor dialético a Hegel, mais precisamente, à dialética do senhor e escravo. Nesta, "senhor" e "escravo" constituem momentos distintos da consciência-de-si que lutam por reconhecimento. Cada uma vê seu ser na outra e para se afirmar, precisa suspender a figura oposta. Nessa luta, elas devem arriscar a própria vida, mostrando-se superior na medida em que se elevam sobre a vida natural. Contudo, não podem negar completamente a outra consciência, já que a morte 
elimina a possibilidade do reconhecimento. Conseqüentemente, a luta deve acabar com uma experiência de negação que ao mesmo tempo conserva os momentos distintos de ambas as consciências-de-si. O resultado acaba por ser "duas figuras opostas da consciência: uma, a consciência independente para a qual o ser-para-si é a essência; outra, a consciência dependente para a qual a essência é a vida, ou o ser para um Outro. Uma é o senhor, outra é o escravo". 5 Nessa relação o escravo reconhece o senhor, mas na medida em que para este o escravo é uma consciência inessencial, o senhor acaba por não conseguir satisfazer seu desejo de reconhecimento por um outro desejo, por uma outra consciência que ele também possa reconhecer. Sua verdade acaba por ser a consciência escrava. Já o escravo, que teve medo de lutar e por isso teve que servir ao senhor, alcança pelo seu trabalho a elevação da vida natural: transcende sua realidade objetiva e se depara com o pensamento abstrato de sua liberdade, tendo a possibilidade de abandonar sua condição de dependência. Nessa dialética, então, as figuras do senhor e do escravo se invertem.

A dialética desenvolvida por Hegel está na base das reflexões de Adorno sobre a relação feminino/masculino. A existência dessa oposição mostra apenas que a imagem da mulher é mero reflexo de uma outra, masculina, e que ambas são necessárias a um pensamento que precisa estabelecer um lado fraco para se afirmar, incapaz de lidar com a diferença a não ser pela violência que dirige ao que é "outro". De acordo com Lee,

\footnotetext{
quando Adorno interpreta o feminino como o "outro" ao masculino, ele não sugere que o feminino é um oposto binário ou polar do masculino como é tipicamente o caso nas teorias pós-modernas da alteridade. O feminino, na leitura de Adorno, é uma alteridade [otherness] que rompe com o conceito totalizante de masculinidade, o qual patologicamente se afirma na sociedade burguesa. ${ }^{6}$
}

Enquanto houver a contraposição entre "feminino" e "masculino" haverá a marca do poder e, conseqüentemente, da submissão. Isso significa que uma possível emancipação feminina não pode acontecer pela reivindicação do poder - masculino - que é negado às mulheres, mas pela recusa em participar da violência dessa racionalidade que ao mesmo tempo permite que alguns dominem e que outros sejam oprimidos. Nesse sentido, a negação deve se dirigir para a ideia de poder e não para sua manifestação, a sociedade masculina, a qual é produto daquela tanto quanto o é a imagem do feminino.

Uma ideia que contribui para que essa imagem do feminino seja possível na sociedade é a de que as mulheres são seres próximos da natureza. Nesse particular, Adorno trata da constituição da identidade feminina a partir da perspectiva teórica freudiana. De acordo com ele, 
tudo o que a palavra natureza designa no contexto da cegueira burguesa não passa de uma chaga da mutilação social. Se é correto o teorema psicanalítico de que as mulheres experimentam sua constituição física como a conseqüência de uma castração, então em sua neurose elas pressentem a verdade. A mulher que se sente como uma ferida, quando sangra, sabe mais a seu próprio respeito do que aquela que se imagina como uma flor porque isso convém a seu marido. A mentira não consiste somente no fato de que a natureza seja afirmada onde é tolerada e implantada, mas o que na civilização passa por natureza é por sua própria substância o mais afastado de toda natureza, a transformação pura e simples de si mesmo em objeto. ${ }^{7}$

O predicado "natural" associado às mulheres traz a marca do antinatural, do social, do poder do indivíduo, porque esse estigma esconde sua própria artificialidade: o fato de que tal imagem é uma construção masculina e que essa suposta essência do feminino nada mais é senão a indisponibilidade delas em relação ao poder. Claramente, isso ocorre não porque falta às mulheres qualquer tipo de qualidade, mas simplesmente porque o poder se concretiza como atributo do "masculino". As mulheres que assumem, então, aquela identidade produzida externamente tornam-se ainda mais "femininas" na medida em que afirmam a submissão ao aceitar que sua constituição "natural” seja o lugar do não-poder.

Ao mesmo tempo, diz Adorno, elas sabem usar essa feminilidade de um modo perverso, o que demostra que a pureza a elas atribuída nada tem de natural, mas "é justamente uma obra do Eu, da censura, do intelecto, e é por isso que ela se encaixa de maneira tão pouco conflituosa no princípio de realidade da ordem racional. Sem exceção, as naturezas femininas se conformam". ${ }^{8}$ Se na concepção freudiana o princípio da realidade é concebido como aquele responsável pela adaptação ou pela realização de um equilíbrio entre a vida pulsional e a social, então, entender que para as mulheres tal conformação acontece quase que espontaneamente é confirmar a ideia de que a constituição da identidade feminina não se opõe à sociedade, antes, surge através desta e a ela se conforma. Essa é uma consequência da defesa de Adorno de que uma subjetividade bem construída passa pelo conflito produzido pelas exigências do princípio do prazer e a impossibilidade de que elas se realizem, algo decorrente do princípio da realidade. Desse modo, se tal adaptação ocorre para as mulheres sem conflitos, é porque há algo de errado com o reconhecimento delas em relação ao seu próprio $\mathrm{Eu}$, ou seja, há algo que se interpõe entre aquilo que deveria aparecer como uma exigência interna e uma limitação ou constrangimento que surge do ego, mas que é orientada segundo as regras sociais. Isso significa que a "pureza" das mulheres não é o resultado desse processo de adaptação, tampouco uma característica essencial, mas uma qualidade aceita como natural e que em função disso se encaixa tão bem nas regras da sociedade que assim a nomeia. Aquela perversão no comportamento e no uso de artifícios que Adorno atribui às ethic@-Florianópolis, Santa Catarina, Brasil, v.13, n.2, p.339-362, jul./dez., 2014. 
mulheres pode ser entendida, portanto, como o resultado desse recalque produzido sobre a identidade delas, o qual vem à tona quando, mesmo que inconscientemente, uma negação dessa "natureza" feminina ocorre, quando há uma recusa em aceitar que seja essa imagem a verdadeira constituição da feminilidade.

É nesse sentido que Adorno afirma, na passagem anteriormente citada, que as mulheres que sofrem sabem mais a seu respeito do que aquelas que se sentem bem porque se adaptaram ao papel que delas é exigido pelos homens. A mulher em sua neurose não é senão aquela que percebe sua própria condição, que consegue ver como está afastada de si própria, pois aquilo que ela pensa sobre si mesma entra em conflito com a imagem que dela se tem na sociedade. Desse modo, a histeria, por exemplo, poderia ser uma indicação, ainda que nãoelaborada e não-teórica, mas nem por isso menos verdadeira, sobre a falsidade da própria constituição feminina. Nela poder-se-ia ver que a castração, como a ausência de poder, existe, a qual até poderia ser considerada positiva ao não compartilhar dessa dominação. Porém, por ser ela precisamente o seu oposto, ou seja, o dominado, é encarada por Adorno de forma negativa. A histeria confirmaria, assim, a violência presente na constituição da identidade feminina e de que são vítimas, não porque são excluídas do poder, mas, sobretudo, pelo fato de se tornarem objetos dele, por sua própria constituição depender de um outro masculino. Isso leva Adorno a dizer que "a glorificação do caráter feminino implica a humilhação de todas aquelas que o possuem", 9 pois exaltar as qualidades supostamente "femininas" é aceitar a opressão e violência que as cria e que subjuga as mulheres ao poder exercido pela sociedade.

A incorporação do ideal de feminilidade também se manifesta sutilmente no comportamento das mulheres. Adorno chama a atenção para uma atitude banal da mulher que atende ao telefone e proporciona ao ouvinte, pelo tom de sua voz, uma imagem de sua beleza. Segundo Adorno,

\begin{abstract}
pela voz de toda mulher que fala ao telefone é possível saber se quem fala é bonita. O tom reflete, pela segurança, pela naturalidade, pela maneira como se escuta a si mesmo, todos os olhares de admiração e de desejo que sempre foram dirigidos a ela. Ela expressa o duplo sentido latino da palavra graça: agradecimento e ato de clemência. O ouvido percebe o que é destinado ao olho, porque ambos vivem da experiência de uma única beleza. É algo reconhecido já na primeira vez: citação familiar do jamais visto. ${ }^{10}$
\end{abstract}

De acordo com essa passagem, a fala da mulher é capaz de trazer à tona indícios do modo como ela se relaciona tanto consigo mesma quanto com a sociedade. Assim, as qualidades como "segurança" e "naturalidade" poderiam ser vistas como características de ethic@- Florianópolis, Santa Catarina, Brasil, v.13, n.2, p.339-362, jul./dez., 2014. 
uma relação harmoniosa, a qual concilia a imagem que a mulher tem de si própria com aquela que os outros sustentam em relação a ela. Ou seja, aquela que é tratada como uma mulher bela e assim se sente, exibe na própria maneira de se expressar e de se dirigir aos outros a segurança de quem não se encontra de algum modo excluída do convívio social pela inadequação aos padrões aceitos. A beleza que lhe é atribuída reforça a própria "feminilidade", a qual então se manifesta no trato amável, agradecido e condescendente, que se apresenta assim, porém, somente porque tal atitude já expressa em si a alienação sobre a situação da mulher. Ela reproduz, como se lhe fosse natural, a imagem que se constrói para ela, age segundo modos que lhe são socialmente atribuídos e reflete, dessa maneira, uma dominação oculta na aparente harmonia entre o seu ser e o outro. Adorno aponta, assim, para a conformidade existente entre a representação da mulher e aquela que se origina no exterior, as quais, uma vez unidas, constituem a identidade feminina, de tal modo que se torna possível reconhecer uma mulher bonita simplesmente por ela se comportar de acordo com o que se espera de mulheres com tal característica. Por essa razão, a "graça" com que ela se exibe é tanto expressão de um agradecimento, uma vez que ela sabe o quão apreciada é e age então com suavidade, naturalidade e elegância, mas consiste também em uma imagem de dor e de piedade por sua própria condição, revestida por uma doçura e bondade de quem se rendeu e aceitou seu destino.

A "beleza feminina", e todo o conflito que essa expressão carrega em si, é tema de outro aforismo presente nas Minima Moralia. Nele, Adorno discute a relação entre a beleza e a felicidade:

as mulheres de beleza excepcional estão condenadas à infelicidade. Mesmo aquelas favorecidas por todas as condições, a quem assistem nascimento, riqueza e talento, parecem como que perseguidas ou possuídas pela ânsia de destruição de si mesmas e de todas as relações humanas de que participam. Um oráculo coloca-as diante da escolha entre destinos fatais. Ou trocam prudentemente a beleza pelo sucesso, e pagam então com a felicidade pela condição deste último; como não podem mais amar, elas envenenam o amor que lhes é votado e terminam com as mãos vazias. Ou o privilégio da beleza dá-lhes coragem e segurança para repudiar o acordo da troca. Elas levam a sério a felicidade que sua pessoa promete e não são avaras consigo mesmas encontrando na inclinação de todos a confirmação de que não precisam de dar provas de seu valor. Em sua juventude possuem essa escolha. Isso deixa-as sem escolha: nada é definitivo, tudo pode ser imediatamente substituído. Muito cedo, sem muita reflexão, elas se casam e com isso comprometem-se com condições demasiado terra-a-terra, alienam-se em certo sentido do privilégio da infinita possibilidade, rebaixam-se à condição de seres humanos. ${ }^{11}$

A razão pela qual ambos os destinos são inevitáveis se pode entender pelo fato de que tal fatalidade se aplica somente a um determinado grupo de mulheres, ou seja, àquelas 
excepcionalmente bonitas. De antemão, elas se encontram sujeitas a um imperativo que, por um lado, lhes faz concessões, por outro, exige algo valioso em troca, a própria liberdade, que uma vez concedida, não pode ser mais recuperada. Justamente por estarem subsumidas a uma ideia de beleza dentro da sociedade burguesa, já se relacionam com esta e por ela são determinadas. Não importa se recusam a beleza e optam por se realizarem para além de um ideal de feminilidade, ou se o aceitam por acreditarem que o uso dessa qualidade dissolverá qualquer barreira a uma eventual troca de objetivos no futuro. A consequência, para qualquer uma das escolhas é, segundo Adorno, a infelicidade. Como ele afirma no aforismo acima citado, a mulher que troca a beleza pelo sucesso passa a ter que conviver com as mazelas que também ele traz, pois o "sucesso" na sociedade capitalista também requer sacrifícios. Quem se decide por ele, portanto, entrega uma parte de si, uma vez que vencer nesta sociedade é dominar e deixar-se dominar, o que é incompatível com a felicidade na medida em que a violência exigida para se realizar tem como preço a renúncia sobre a possibilidade de se autodeterminar, portanto, também de buscar a felicidade, a qual passa a depender mais do acaso do que da determinação individual. Mesmo assim, Adorno caracteriza tal troca como prudente, o que significa que pelo menos há nessa atitude uma forma de resistência: uma vontade em confrontar valores e buscar essa autodeterminação que mais tarde se revelará ilusória, não porque o sucesso não seja possível, mas em função dessa troca esconder em seu princípio os custos que ela exige para se concretizar. Quem troca a beleza pelo sucesso, porém, mostra já a suspeita de que viver sob a dependência de outro, do jugo alheio, não condiz com a felicidade.

A mulher que, por outro lado, decide assumir o valor da beleza e recusar trocá-la por qualquer outra coisa, compromete-se, do mesmo modo, com a impossibilidade de se realizar e ser feliz. O futuro que parece não ser condenado por essa escolha revela-se, contudo, irrevogável; ela engana-se ao acreditar que a beleza, uma vez que lhe concede certos privilégios, como o de ser aceita e apreciada, garantirá que essas mesmas concessões se realizem no futuro. É assim que essa mulher se engana, julga ter o domínio de sua vida quando, na verdade, já está condenada a viver as consequências de assumir a si mesma do modo como é, ou seja, de valorizar uma qualidade passageira, acreditando que as vantagens presentes serão preservadas ao longo da vida. Tal crença, contudo, lhe possibilita usufruir dos prazeres que, também efêmeros, constituem esse seu modo de existir. Quando se casam, diz Adorno, tomam uma decisão definitiva e se tornam meros seres humanos. Aquela possibilidade infinita que incentivara a recusa em realizar a troca passa a ser, agora, 
inexistente, embora ainda possa haver a sensação de que ela persista. E é esse pensamento, quando confrontado com as circunstâncias mundanas, que faz surgir o caráter destrutivo identificado por Adorno como uma busca doentia por algo que já se perdeu e que, entretanto, acredita-se ainda possuir. Como diz ele, "é precisamente porque foram uma vez hors concours que ficam para trás na concorrência, a que agora se dedicam maniacamente". ${ }^{12}$ Assim, tanto o passado quanto o presente se esvaecem frente à ideia de que algo melhor está por vir, de que aquela expectativa anterior não pode ter se convertido em um logro e que deve, por isso, ser perseguida. Tal busca é, segundo Adorno, um equívoco, pois "o encantamento dissolve-se no momento em que, em vez de apenas representar uma esperança, se deixa estabelecer e domesticar. Mas quem não é mais irresistível transforma-se logo em vítima: ela se vê submetida à ordem que outrora podia ignorar". ${ }^{13}$

É possível reconhecer nessa crítica de Adorno uma espécie de aporia. Nas passagens acima citadas, a situação da mulher deriva mais da própria ordem social do que de uma repressão masculina. Apesar de a configuração social ser predominantemente patriarcal, poder-se-ia pensar que também para os homens a possibilidade da felicidade é impedida, uma vez que as razões para a falta de liberdade se estendem para além de uma determinação de gênero. A relação entre beleza e felicidade que Adorno aponta talvez seja apenas um exemplo de algo que acometa as pessoas de modo mais geral, por isso, sua crítica não significa uma visão parcial em relação à questão. Isso tem a ver com o que Adorno diz na seguinte passagem: "o pensamento dialético se opõe à reificação no sentido também que se recusa a confirmar cada coisa de individual em sua individuação e separação: ele determina a individuação precisamente como um produto do universal". ${ }^{14}$ Ou seja, tratar da temática da feminilidade é não reduzir o pensamento a um pólo que o tornaria, por isso, parcial. Ao contrário, é preciso olhar para o objeto, assim como para o seu oposto e vê-los a partir de uma totalidade à qual ambos pertencem, de tal modo que se possa chegar mais perto da falsidade presente na realidade. Reconhecê-la, portanto, é também, ainda que de modo inverso, se aproximar da verdade, pois, como afirma Adorno,

a razão dialética, contrária à razão dominante, é desrazão: é tão-somente na medida em que desmascara e suprassume [aufhebt] a razão dominante que ela própria se torna racional. (...) Tendo reconhecido o universal dominante e suas proporções como doentes - e em sentido literal marcados pela paranóia, pela "projeção pática" -, então tudo aquilo que se apresenta, segundo os critérios da ordem estabelecida como doente, errado, paranóico e até mesmo como "doido" torna-se para ela apenas um germe da convalescença, e é válido afirmar, hoje como na Idade Média, que somente os bobos dizem a verdade a seus senhores. Desse ponto de vista, o dever do dialético seria auxiliar essa verdade dos bobos a atingir a consciência de sua 
própria razão, sem o que ela certamente sucumbiria no abismo daquela doença ditada impiedosamente pelo bom senso dos outros. ${ }^{15}$

Nesse sentido, até mesmo a literatura pode contribuir para uma melhor compreensão da sociedade, na medida em que também ela expõe, às vezes pelo seu exagero em descrever uma situação social, aquilo que de imediato pareceria absurdo, se não fosse o fato de ser justamente esse contrário o indício de verdade do objeto que se busca entender. ${ }^{16}$ Uma reflexão sobre a figura da mulher pode ser realizada não apenas analiticamente, mas, sobretudo, a partir das próprias contradições sociais reveladas pela arte, de tal forma que o contexto em que a imagem do feminino está imersa contribua para uma explicitação mais integral do seu papel na sociedade. Um dos exemplos literários do qual se extrai uma representação da feminilidade encontra-se na obra de Proust, a qual é analisada por Adorno do ponto de vista da decadência do amor, mas que não exclui uma consideração sobre o caráter astucioso das mulheres. A avaliação negativa da personalidade feminina, que logra o amante por meio de sua beleza e falsa atenção, é um sintoma social, uma vez que exibe no tratamento quase piedoso em relação àquele que a ama uma violência da qual também ela é vítima. Isso fica mais claro quando a argumentação adorniana é acompanhada em todo o seu desenrolar:

\begin{abstract}
Proust faz uma alérgica prestação de contas do que estava por ser infligido ao amor. A relação de troca, à qual o amor opõe uma resistência parcial ao longo da era burguesa, absorveu-o por completamente; a última imediatidade cai vítima do distanciamento em que os contratantes se encontram de todos os demais. O amor esfria pelo valor que o Eu atribui a si mesmo. Amar, em seu caso, aparece-lhe como um mais amar e quem ama mais põe-se no erro. Ele se torna suspeito aos olhos da amada e, devolvido a si mesmo, sua inclinação passa a sofrer de uma crueldade possessiva e de uma imaginação autodestrutiva. "As relações com a mulher que se ama", diz Proust no Temps retrouvé, "podem permanecer platônicas por outra razão que a virtude da mulher ou a natureza pouco sensual do amor que ela inspira. Esta razão pode ser a incapacidade do amante, demasiado impaciente pelo excesso mesmo de seu amor, de aguardar sem suficiente fingimento de indiferença o momento de obter o que deseja. Ele volta sempre à carga. Não cessa de escrever àquela que ama, procura vê-la o tempo todo; ela recusa, ele fica desesperado. A partir desse momento, ela compreende que, se lhe concede sua companhia, sua amizade, esses bens já hão de parecer tão consideráveis a quem se acreditou privado deles, que ela pode se dispensar de dar mais do que isso e aproveitar-se de um instante em que ele não consegue mais ficar sem vê-la, em que ele se encontra disposto a terminar a guerra a qualquer preço, para lhe impor então uma paz cuja primeira condição será o platonismo das relações... As mulheres adivinham tudo isso e podem se oferecer o luxo de jamais se darem àqueles em que sentem, se forem nervosos demais para lhe esconder isto desde o início, o desejo insaciável que têm delas". ${ }^{17}$
\end{abstract}

Adorno procura mostrar que o amor se integrou ao cálculo característico da racionalidade instrumental predominante na sociedade burguesa. Se a realização de fins é o 
modo pelo qual o organismo social funciona, tendo como objetivo principal a autoconservação, então, também os indivíduos, imersos na totalidade, refletem essa intenção, de tal modo que, inclusive o amor, acabe por se enquadrar nesses moldes. Cada um dos amantes destina ao outro somente aquilo que acredita ser conveniente para a sua própria realização. Nesse particular, as mulheres, conforme a descrição de Proust indicada por Adorno, distinguem nitidamente os limites em relação aos quais irão agir satisfazendo parcialmente os desejos cada vez mais acanhados do amante e conservando seu próprio eu, sem se permitir ultrapassar a barreira entre si e o outro. Contudo, afirma Adorno, "a dissolução objetiva da sociedade manifesta-se subjetivamente no fato de que o impulso erótico se tornou fraco demais para ligar as mônadas voltadas para a autoconservação, como se a humanidade imitasse a teoria física da explosão do universo". ${ }^{18}$ Além disso, há o que Adorno identifica com a perda do prazer no espaço mesmo do sexo. Se antes este representava uma entrega total, agora se converteu em doença, na obsessão pela satisfação de um impulso meramente fisiológico. De acordo com Adorno,

quando Casanova dizia de uma mulher que ela era sem preconceitos, ele queria dizer que nenhuma convenção religiosa a impedia de se entregar; hoje, sem preconceitos seria a mulher que não acreditasse mais no amor, que não se deixasse enganar investindo mais do que pode esperar em retorno. ${ }^{19}$

A crítica de Adorno, mais uma vez, aponta para uma certa inversão de valores, para uma mudança subjetiva na constituição do indivíduo que resulta em um interesse cego pela autoconservação e que exclui a consideração pelo outro, exceto na forma de um meio necessário para se atingir um propósito. A atrofia do sentimento, do respeito e do prazer são, nessa perspectiva, reflexos da dissolução do indivíduo face à totalidade. Nem o homem que busca obcecadamente o amor da mulher, nem ela que se recusa a entregar-se completamente, podem ser vistos isoladamente, pois tais comportamentos só são compreensíveis à luz de uma reflexão mais ampla sobre a situação social.

\section{A crítica dialética ao casamento}

Um lugar em que um olhar imediato pode trair a verdade é exemplificado nas Minima Moralia pelo casamento. Nele, a complexidade da relação entre homem e mulher pode se estender a tal ponto que para entendê-la em sua totalidade é necessária não apenas uma percepção aguda dos elementos que a compõem, mas uma reflexão dialética sobre a situação, 
sobre sua face negativa. Essa exigência pode ser encontrada, por exemplo, no aforismo 111, o qual mostra que o poder que geralmente se atribui ao homem nem sempre está de fato com ele. Contudo, mesmo quando concedido à mulher, significa uma espécie de "vitória" sobre a própria derrota. A reflexão sobre o aforismo pode iniciar pelo seu próprio título: Filemon e Baucis. De acordo com a mitologia, os deuses Júpiter e Mercúrio, disfarçados de mortais, visitaram a cidade de Frígia. De casa em casa, procuraram por comida e abrigo, mas ninguém os ajudava, exceto um casal de velhinhos, cuja mulher se chamava Baucis e o homem Filemon. Era um casal pobre, feliz, que habitava uma casa humilde e que recepcionou Júpiter e Mercúrio oferecendo-lhes uma ceia. Quando os velhinhos notaram que a jarra de vinho com a qual serviam os hóspedes não se esvaziava, mesmo servindo-lhes continuamente, maravilharam-se com a presença dos deuses e desculparam-se por servir uma ceia pobre, dispondo-se, então, a matar um ganso que tinham em casa. O velhinho correu atrás do animal sem sucesso, para divertimento dos deuses, os quais, então, disseram a Filemon que aquilo não lhes era necessário. Júpiter e Mercúrio vingaram-se dos outros habitantes destruindo a cidade, mas pouparam Filemon e Baucis, transformando sua casa em templo e ofertando-lhes um pedido. O casal desejou ser guardião do templo e não viver um mais do que o outro. Assim, depois de algum tempo, quando já eram então muito idosos, um foi transformado em carvalho e o outro em tília, permanecendo juntos porque as árvores cresceram a partir de um mesmo tronco.

A história dos velhinhos que escolheram viver juntos até a morte, e inclusive nela permanecer unidos, serve, ironicamente, como título para um aforismo que mostra, justamente, a inverdade do casamento. Nele, Adorno critica tanto o papel superior atribuído pela sociedade ao homem, quanto o comportamento perverso da esposa. O homem, sempre visto como forte, torna-se aos olhos da mulher um ser fraco e merecedor de uma espécie de compaixão. A força masculina se transforma em fraqueza, a qual é tratada de modo cruel pela mulher como vingança por sua própria submissão. Adorno diz: "o tirano doméstico faz-se ajudar por sua mulher para vestir o sobretudo. Zelosa ela presta esse amoroso serviço acompanhando-o com um olhar que diz: o que é que eu posso fazer, deixem que tenha essa pequena alegria, ele é assim, apenas um homem". ${ }^{20}$ A "superioridade" do homem é tratada pela esposa de forma desdenhosa, o que a torna cúmplice daquela mesma dominação expressa na própria caracterização do homem como tal. O "amoroso serviço" não é senão uma forma de desprezo disfarçada por um ato aparentemente carinhoso, o qual, em algum momento, não 
esconderá mais a raiva que nele está enraizada e virá à tona na forma de um ataque àquele que se presume ser uma pessoa amada. Adorno continua:

o casamento patriarcal vinga-se do senhor com a indulgência da mulher, indulgência que se transformou numa fórmula nas queixas irônicas acerca da choramingação e dependência dos homens. Por baixo da ideologia mentirosa que apresenta o homem como superior oculta-se uma ideologia secreta, não menos mentirosa, que o rebaixa ao nível de um inferior, de uma vítima de manipulações, manobras e enganos. O herói de chinelos é a sombra daquele que tem que ir lá fora encarar a vida hostil. ${ }^{21}$

Assim, a esposa, a qual vive sob o rótulo de ser "fraca", inverte a lógica da dominação apresentando o marido como um ser dependente e que precisa dela para fazer até mesmo coisas triviais. Adorno não critica tal atitude em um sentido moralista, como se fosse um sinônimo de falsidade ou incoerência em relação ao próprio compromisso sobre o qual se baseia o casamento. O que ele faz é enfatizar que aquele comportamento traz consigo marcas de uma dominação que atinge tanto o homem quanto a mulher, sem com isso negar que são elas, as mulheres, vitimas de uma violenta opressão exercida pelos homens. Ele acusa o próprio casamento como uma instância que tenta ainda conservar uma humanidade, preservar algum sentimento de atenção e respeito mútuo, o que, porém, não encontra espaço na sociedade capitalista.

Toda a repressão infligida sobre as mulheres, portanto, ressurge como uma atitude hostil em relação àqueles que a causam. $\mathrm{O}$ desprezo com que são tratadas transforma-se em rancor que se traveste no tratamento zeloso para com o marido. Embora pareça ser expressão de cuidado e amor, tal tratamento manifesta um sentimento mais profundo de negação do poder que é atribuído a ele. Essa negação, porém, não tem espaço para se efetivar e, por isso, aparece distorcida, mascarada e devido à impossibilidade de uma real manifestação, também exibe uma violência da qual é produto. No mesmo aforismo, Adorno afirma:

com a mesma perspicácia estreita com que a esposa julga o esposo também os adultos são em geral julgados pelas crianças. Na desproporção entre a pretensão autoritária e o seu desamparo, desproporção que se manifesta necessariamente na esfera privada, há algo de ridículo. Todo casal que se apresenta junto é cômico, e é isso que a paciente compreensão da esposa procura compensar. Rara a mulher casada há algum tempo que não revele em cochichos as pequenas fraquezas do marido. Uma falsa proximidade incita à maldade, e na esfera do consumo o mais forte tem as mãos sobre as coisas. ${ }^{22}$

Aqui fica mais claro como o casamento acaba por se constituir em uma farsa, condenado ao fracasso e à inverdade porque desde seu surgimento já tem em sua base um 
abismo que não consegue fechar. A desproporção de que Adorno fala pode ser entendida no sentido das imagens falsas que se formam em torno das figuras do homem e da mulher. Ao masculino é atribuída uma imagem de força, superioridade e poder, que na intimidade, contudo, revelam-se para a mulher de modo diferente, justamente porque tais qualidades são ilusórias. A imagem dela também é construída e lhe é imposta como algo natural, que faz parte de sua "essência" e que, portanto, não pode ser alterada. Entretanto, essas construções não resistem ao casamento, uma vez que nele a intimidade pode ser estendida ao seu limite e a verdade sobre ambas as partes inevitavelmente aparece. Com a verdade, porém, não vem a mudança no modo como cada um trata o outro, ao contrário, aquelas imagens permanecem e as pessoas tentam conservá-las como se fossem mesmo reais. Daí Adorno dizer que todo casal que se apresenta junto é cômico, pois é possível perceber o esforço de cada um a fim de manter a inverdade que é inerente ao casamento na sociedade capitalista. A mulher que percebe o abismo entre aquilo que o esposo é e o que se diz da figura dele em geral, tenta compensar esse vão com compreensão, com zelo, mas revelando por meio desse seu comportamento a verdade sobre ele. É nesse sentido, então, que Adorno afirma existir aí uma dialética do senhor e do escravo:

\begin{abstract}
a dialética hegeliana do senhor e do escravo ainda é válida como dantes na ordem arcaica do lar e vê-se reforçada porque a mulher persiste de um modo obstinado nesse anacronismo. Como matriarca reprimida, ela transforma-se em senhor precisamente onde tem que servir, e o patriarca só precisa aparecer como tal para ser uma caricatura. Essa dialética simultânea das épocas apresentou-se ao olhar individualista como "luta dos sexos". Ambos os adversários estão errados. Ao desmistificar o homem - cujo poder repousa sobre o fato de ganhar dinheiro, alardeado como próprio do ser humano - a mulher expressa ao mesmo tempo a inverdade do casamento, no qual ela busca toda sua verdade. Não há emancipação sem a emancipação da sociedade. ${ }^{23}$
\end{abstract}

Tal é o movimento dialético que resulta na inversão das figuras da consciência-de-si e que é utilizada por Adorno para ilustrar como no casamento também as figuras do homem e da mulher se transformam. A imagem do homem representa na sociedade a superioridade, construída à custa da liberdade da mulher que precisa ser fraca para dar suporte a ele. Sua dependência torna-se condição para que o homem se afirme como senhor. No casamento, porém, essa oposição se desfaz, mostrando sua inverdade, a qual consiste, justamente, em ser também o esposo fraco. A mulher, ao perceber isso, vinga-se de sua submissão e da sua sempre dita fraqueza trazendo à tona, sutilmente, a dependência do marido, mas sem romper efetivamente com esses valores falsamente construídos. Ao fazer isso ela se torna forte, mas, 
ao mesmo tempo, mostra o quão distante da verdade está o casamento, pois mesmo sendo a esfera da intimidade, da união e, supostamente, de respeito e amor mútuo, nele as diferenças não são elaboradas. Ao invés da verdade de cada uma das partes ser expressa, ela é camuflada para que a aparência das imagens atribuídas à mulher e ao homem ainda se sustentem. Assim, a atitude da esposa não a libera da submissão, nem torna fraco o esposo, uma vez que ainda está presa aos moldes sociais de dominação. É por isso que sem a emancipação da sociedade, tampouco a emancipação feminina é possível, porque a liberação da mulher não terá sentido em uma sociedade na qual também os homens são vítimas de uma racionalidade que torna todos objetos de manipulação.

O casamento, portanto, se apresenta como uma farsa quando se eleva sobre essas falsas representações de homem/mulher e trai a pretensa intimidade, cumplicidade e respeito que deveriam existir entre os pares. Além disso, constitui-se em uma falsidade na medida em que nenhuma das partes se relaciona com o outro diretamente, mas por meio do papel que se espera de cada um na relação, o qual emerge de exigências sociais distorcidas. Dessa forma, como defende Adorno,

o casamento, cuja paródia vergonhosa sobrevive numa época que retirou o solo do direito humano ao matrimônio, serve hoje, na maior parte dos casos, ao ardil da autoconservação: porquanto cada um dos conjurados atribui ao outro a responsabilidade por todo mal que comete, enquanto, na verdade, continuam ambos a viver juntos uma vida sombria e pantanosa. ${ }^{24}$

Por servir como instância de preservação de interesses, o casamento perde a possibilidade de se apresentar como uma esfera em que ainda sobreviveriam traços de humanidade. $\mathrm{Na}$ sociedade capitalista, como Adorno mostra, a união acaba por perder sua legitimidade justamente ao incorporar os mesmos mecanismos que regem a sociedade e que bloqueiam a liberdade que poderia existir no amor. Ao fazer da união um meio para se obter algo, não só a relação se torna um instrumento, como também a pessoa amada se vê limitada por sua condição de dependência. De acordo com Adorno, "um casamento decente seria somente aquele em que ambos possuíssem uma vida própria, independente, sem a fusão que deriva de uma comunidade de interesses imposta pela necessidade econômica, e no qual, em compensação, assumissem livremente a responsabilidade recíproca de um pelo outro". ${ }^{25}$ Tal ideal, contudo, parece não ter espaço na sociedade, pois mesmo aqueles que não buscam na união um ganho material não estão isentos da miséria que se tornou o casamento, já que para eles, os privilegiados em relação a sua situação econômica, "a perseguição de interesses se 
tornou uma segunda natureza - do contrário não manteriam o privilégio". ${ }^{26}$ Assim, não há como se esquivar de participar de uma situação que coloca ambas as partes em uma condição de humilhação por não ser possível a eles, apesar do sentimento que podem ter um pelo outro, estabelecer um tipo de relação isenta da racionalidade que orienta a sociedade na busca pela autoconservação.

\section{Emancipação feminina e emancipação social}

A radicalidade das críticas de Adorno à imagem do feminino é consequência de sua crítica mais ampla à sociedade e à racionalidade instrumental que nela se apresenta. Daí a impossibilidade de isolar o caso das mulheres, o qual surge no âmbito de uma sociedade predominantemente masculina, de outros em que o mesmo princípio de dominação se manifesta. Para Adorno, a violência a que as mulheres estão expostas, embora possa ser compreendida em sua particularidade, não pode ser desvinculada de uma violência sofrida de modo geral pelos indivíduos. Enquanto houver dominação e sofrimentos injustificáveis nessa sociedade, torna-se muito difícil falar em uma emancipação feminina, mesmo que as mulheres avancem na conquista de seus direitos. No aforismo intitulado Exumação, Adorno argumenta que mesmo com a integração das mulheres na economia por meio do trabalho assalariado, com o "desencantamento da família" ou com uma liberação sexual, ainda que superficial, a emancipação feminina não ocorre efetivamente, uma vez que essas mudanças acontecem dentro de uma sociedade tradicional em que a dominação persiste como princípio. Segundo Adorno,

na admissão das mulheres em toda espécie de atividade supervisionada esconde-se o prosseguimento de sua desumanização. Na grande empresa elas continuam a ser o que eram na família: objetos. Não se deve pensar apenas em sua miserável jornada de trabalho profissional e em sua vida no lar - situação que mantém de maneira absurda condições de trabalho fechada, em meio às condições do trabalho industrial -, é preciso pensar nas próprias mulheres. ${ }^{27}$

A mudança ocorreria, portanto, em um pano de fundo estático que impede sua completa realização. Assim, o que se tem é a aparência de uma conquista, a qual, contudo, ao ser interpretada em um contexto mais amplo, mostra-se absorvida por mecanismos que são contrários à própria emancipação. É dessa maneira que a saída da mulher para o trabalho acaba por ser não uma conquista, mas uma espécie de concessão da sociedade masculina. 
Nesse sentido, a mulher, ao adentrar o mundo do trabalho, paga o preço de uma submissão agora expressa em outros moldes, não muito menos repressores do que antes e que se mostra, por exemplo, no fato de que durante muito tempo elas não podiam ocupar cargos de liderança, exercendo, então, atividades não muito bem avaliadas socialmente ou mal-remuneradas em comparação com atividades iguais desempenhadas pelos homens. Como afirma Lee, "esse ato de admitir mulheres nas atividades sociais das quais elas foram anteriormente excluídas não é um passo em direção à emancipação, mas antes um gesto malfadado que enfraquece a habilidade das mulheres em reconhecer a verdadeira extensão da sua opressão". ${ }^{28}$

A crítica de Adorno à aparente emancipação feminina nas Minima Moralia aponta para a necessidade de se compreender os mecanismos de dominação sociais que impedem não somente as mulheres, mas também os homens, de serem livres. Na crítica de Adorno ao casamento, discutida na seção anterior, fica evidente que as imagens criadas acerca do homem também são compostas por várias mediações. As características de força ou superioridade, por exemplo, dissolvem-se quando são objetos da crítica dialética. Isso não significa, porém, que não se possa reconhecer a posição de maior fragilidade encontrada pelas mulheres, tradicionalmente formadas em uma lógica que as apresenta como inferiores ou incapazes. Isso faz com que elas próprias, muitas vezes, não reconheçam a situação de repressão em que vivem. Nesse ponto, Adorno faz uma crítica que parece, à primeira vista, carregada de preconceito. Segundo o autor,

\begin{abstract}
espontaneamente, sem impulso em sentido contrário, elas são um reflexo da dominação e identificam-se com ela. Em vez de resolver a questão da mulher, a sociedade masculina estendeu a tal ponto seu próprio princípio que as vitimas não são mais capazes de levantar essa questão. Desde que lhes seja concedida uma certa abundância de mercadorias, elas aceitam com entusiasmo sua sorte, deixam aos homens a tarefa de pensar, difamam toda reflexão como um atentado contra o ideal feminino propagado pela indústria cultural e, de modo geral, se comprazem na nãoliberdade, que consideram como a realização do seu sexo. Os defeitos que são o preço a pagar por isso, em primeiro lugar uma burrice neurótica, contribuem para perpetuar esse estado de coisas. ${ }^{29}$
\end{abstract}

Nessa passagem, pode-se perceber que a falta de reflexão crítica facilita a internalização das imagens produzidas socialmente, fortalecendo, assim, a repressão. As mulheres que aceitam a "natureza" a elas conferida e respondem ao que delas se exige, integram-se à lógica de dominação. Devido ao fato de sua imagem ser construída dentro de uma sociedade masculina que as oprime e determina aquilo que faz parte ou não da sua "natureza", segue-se que a violência está intensamente presente nessa constituição, na medida 
em que a elas é negada a possibilidade de se reconhecerem sem a intermediação dessa figura que surge do exterior. Assim, convivem, desde a formação da sua própria subjetividade, com a violência e dominação. Caso não consigam se separar dessa imagem, aceitam sem resistência - já que lhes aparece como "natural"- o fato de que na sociedade são vítimas de uma opressão, a qual só pode ser vista como tal a partir do momento em que essa imagem de feminilidade for questionada. Para isso, seria necessário se contrapor aos modelos que estabelecem como a mulher deveria ser, muitas vezes disseminados por meio de produtos culturais.

A indústria cultural, nesse particular, participa da construção de representações sobre a figura do feminino. Contudo, o fenômeno é geral, contribuindo para a situação de reificação da consciência ao negar aos indivíduos uma experiência com a cultura que poderia ser formativa e, justamente, dirigida para o esclarecimento e reflexão crítica. Os produtos culturais exibem ideais e transmitem mensagens que poderão ser facilmente absorvidas por seus consumidores. Como afirma Adorno, "o que ela produz não é um estímulo, mas um modelo para maneiras de reagir a estímulos inexistentes. Daí os entusiásticos títulos musicais nos cinemas, a ridícula linguagem infantil, o tom popular que desperta a atenção (...)" ${ }^{30} \mathrm{~A}$ indústria cultural opera no sentido não de fornecer aos seus consumidores aquilo que eles desejariam, mas de provocar neles as reações que ela necessita para sua própria manutenção. Por ser parte e instrumento de uma sociedade que se estrutura sobre a dominação, os produtos da indústria cultural mantêm os padrões tradicionais sobre aquilo em que consistiria a natureza do feminino, fazendo com que tantos as mulheres se comportem de acordo com eles, quanto com que os homens também os sigam. Seria preciso uma atitude crítica para romper com esse processo, a qual, porém, é precisamente negada pela forma com que a indústria cultural atua na formação da consciência dos indivíduos. Adorno aponta, desse modo, para a reificação que se intensifica, tornando os indivíduos uma massa que se adapta às tendências totalizadoras da sociedade. Para o autor,

o indivíduo deve sua cristalização às formas de economia política, em particular ao mercado urbano. Mesmo como oponente das pressões da socialização, ele permanece sendo seu produto mais característico e a ela semelhante. O que lhe permite a resistência, cada traço de independência, tem sua fonte no interesse individual monadológico e na cristalização deste como caráter. $\mathrm{O}$ indivíduo reflete, precisamente em sua individuação, a lei social preestabelecida da exploração, por mais que esta seja mediatizada. Isso significa também que sua decadência na presente fase não é algo a ser derivado de um ponto de vista individual, mas sim a partir da tendência da sociedade, tal como ela se impõe por meio da individuação, e não como mero adversário desta. ${ }^{31}$ 
Se o indivíduo aparece como expressão de uma tendência objetiva, compreender as formas de reificação que adentram a vida privada do indivíduo significa, igualmente, lançar um olhar para o todo do qual ele faz parte. Nesse sentido, nas Minima Moralia, a crítica feita por Adorno mostra como a vida individual passou a ser administrada segundo uma lógica instrumental vinculada à dominação. $\mathrm{O}$ declínio do indivíduo tem sua razão na força com que a totalidade o suprime, e não por sua própria culpa. Para Adorno, “(...) como a sociedade integral não suprassume [aufhebt] os indivíduos tão positivamente em si mesma, quanto, ao contrário, os comprime numa massa amorfa e dócil, cada indivíduo se horroriza com o processo de absorção que é experimentado como inevitável". ${ }^{32}$ Ao indivíduo torna-se difícil resistir, mas um primeiro passo nessa direção seria afirmar-se por meio de um pensamento capaz de se dar conta da própria condição. Se a tendência social colocada se dirige para a dissolução do indivíduo, voltar-se contra ela significa fortalecer o eu. Adorno identifica situações em que os indivíduos acabam adotando uma atitude justamente contrária, entregando-se aos mecanismos da indústria cultural, ocupando o tempo livre com as mercadorias que lhes são disponibilizadas e com formas de entretenimento cuja estrutura não se distingue daquela encontrada no próprio trabalho. ${ }^{33} \mathrm{~A}$ vida privada se torna, assim, um espaço invadido por tendências objetivas que são absorvidas pelos indivíduos mesmo quando eles acreditam estar agindo no sentido de se oporem a elas. Adorno fornece um exemplo desse tipo de atitude:

\begin{abstract}
doing things and going places é uma tentativa do sensorium no sentido de desenvolver uma espécie de defesa de estímulos contra a coletivização que nos ameaça, de exercitar-se para ela, na medida em que as pessoas, precisamente naquelas horas reservadas na aparência à liberdade, se educam como membros da massa. A técnica aí é revidar o perigo onde for possível com outro maior. Portanto, sacrificando-se cada vez mais seu próprio Eu, vive-se, em certo sentido, ainda pior do que se esperava ter que viver. Ao mesmo tempo, através desse excesso lúdico de auto-renúncia, aprende-se que não seria mais difícil, mas sim mais fácil, viver a sério sem o Eu. ${ }^{34}$
\end{abstract}

Nesse contexto de negação do próprio eu, emergem no indivíduo anseios que precisam ser atendidos. Não se pode sentir tédio e, para isso, é necessário estar todo o tempo ocupado. Contudo, os produtos da indústria cultural, por se apresentarem sempre os mesmos, ainda quando prometem a novidade, não proporcionam ao indivíduo um efetivo divertimento. Alimentam-se, porém, justamente dessa necessidade provocada pelo vazio que o indivíduo experimenta, mas que, na verdade, não pode ser preenchido. Como mostra Adorno, "o tédio 
de que as pessoas fogem é um mero reflexo do processo de fuga no qual elas há muito tempo estão envolvidas. É por essa razão, somente, que o monstruoso aparato de diversão mantém-se vivo e se expande cada vez mais, sem que um único indivíduo dele extraia divertimento". ${ }^{35}$ Assim, a relação do indivíduo com as forças objetivas da sociedade é tensa, pois ao mesmo tempo em que elas o pressionam para que ele as absorva, há um movimento de fuga, o qual, porém, pode ser limitado se a saída encontrada for essa descrita por Adorno, uma alternativa que, no fundo, pressupõe o abandono do próprio eu.

Considerando essa perspectiva que Adorno apresenta nas Minima Moralia, as imagens do feminino devem ser pensadas em seu entrelaçamento com outras forças sociais, as quais compõem tais representações. Não são somente as mulheres, portanto, que têm sua subjetividade formada a partir das imagens associadas a uma pretensa natureza feminina. Os indivíduos, de forma geral, sofrem esse mesmo processo, contra o qual somente a força do eu seria capaz de opor resistência. Para isso, é necessária a crítica dialética, capaz de chegar a um núcleo de verdade por meio do enfrentamento das contradições. Por meio dela, pode-se vislumbrar o ideal de uma sociedade emancipada, aquela em que, como diz Adorno, "ninguém mais passe fome", ${ }^{36}$ na qual as finalidades da vida humana não sejam atravessadas pelos interesses econômicos, nem pelo poder dominante. Uma humanidade que, segundo o autor, poderia se liberar da necessidade e renunciar aos objetivos de produção e desenvolvimento. Nessa sociedade liberada da totalidade, não faria sentido distinguir entre o masculino e feminino, pois o humano estaria acima de tais determinações.

\section{Considerações finais}

A crítica de Adorno, como se tentou mostrar, não se aplica exclusivamente às mulheres. Embora estas sofram uma repressão exercida, sobretudo, pelo poder masculino, partilham de uma violência totalizadora. Adorno enfatiza que a consideração da mulher como um ser puro ou associado à natureza é algo artificial e serve para perpetuar o estado de dominação a que elas são submetidas. Tal princípio é o mesmo que se desenvolve amplamente na sociedade, como a sua ideia fundante que a natureza deve ser dominada para que os homens possam ser livres. Desse modo, a crítica à impossibilidade de uma emancipação feminina em uma sociedade tradicional revela a necessidade de que toda uma forma de pensamento se altere, assim como as práticas dele decorrentes. Desse modo, se consideradas na perspectiva da filosofia adorniana, as reflexões sobre a imagem do feminino 
deve ser tratadas como partes da crítica à razão a que Adorno foi fiel e que não permite conceber um ideal de emancipação para as mulheres desvinculado de uma emancipação para toda a sociedade. Seria preciso desmistificar aquilo que é propriamente masculino ou feminino e priorizar o humano, de tal forma que a liberdade pudesse ser pensada e buscada para todos. Os meios para se alcançar tal objetivo não estão claramente definidos, mas certamente partem da exigência de um pensamento crítico, capaz de estabelecer uma relação diferenciada com a realidade, encontrando um núcleo de verdade nas contradições que ela apresenta. 


\section{Notas:}

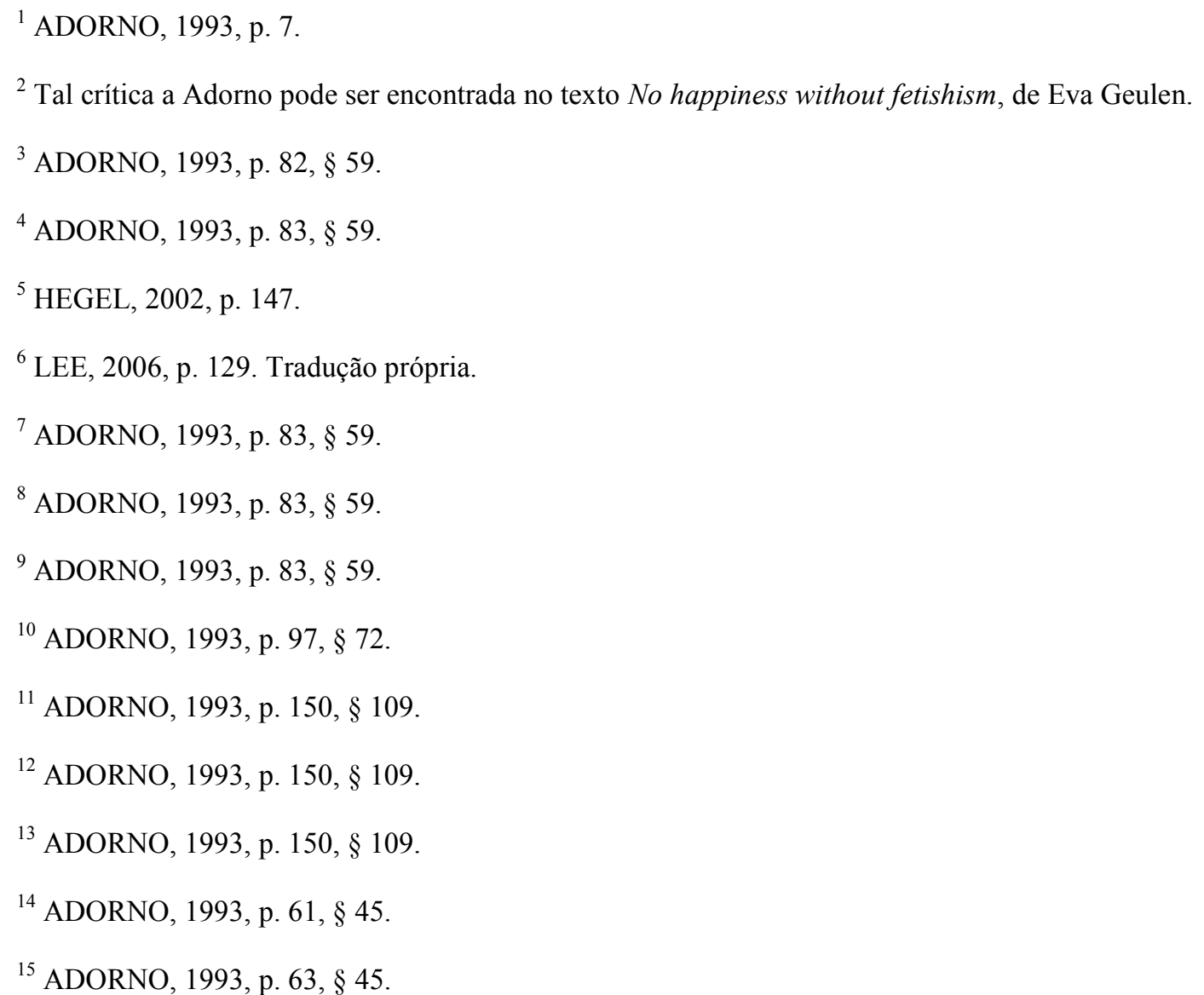

${ }^{16}$ Basta ler alguns aforismos em que Adorno comenta a obra de Goethe, Karl Kraus, Proust ou Kafka com autores que, por meio de suas obras, souberam ou antecipar traços sociais que logo se incorporariam à realidade ou, no caso do último, utilizando-se do absurdo, conseguiu alcançar uma verdade sobre a sociedade de seu tempo. São exemplos, portanto, de como a verdade se revela pelo seu inverso, pelo falso, pelo absurdo, pelo que não é estritamente real, mas que a ele se relaciona através da obra, a qual é sempre mediada pela objetividade. Tais considerações podem ser encontradas nas Minima Moralia, por exemplo, nos aforismos "Para uma dialética do tacto", "Como parece doentio tudo o que está em devir"”, ou em textos como Anotações sobre Kafka (Cf. Adorno, 1991).

${ }^{17}$ ADORNO, 1993, p. 147, § 107.

${ }^{18}$ ADORNO, 1993, p. 147, § 107.

${ }^{19}$ ADORNO, 1993, p. 148, § 107.

${ }^{20}$ ADORNO, 1993, p. 151, § 111.

${ }^{21}$ ADORNO, 1993, p. 151, § 111.

${ }^{22}$ ADORNO, 1993, p. 152, § 111.

${ }^{23}$ ADORNO, 1993, p. 152, § 111.

${ }^{24}$ ADORNO, 1993, p. 24, § 10.

${ }^{25}$ ADORNO, 1993, p. 24, § 10. 
${ }^{26}$ ADORNO, 1993, p. 24, § 10.

${ }^{27}$ ADORNO, 1993, p. 80, § 57.

${ }^{28}$ LEE, 2006, p. 128. Tradução própria.

${ }^{29}$ ADORNO, 1993, p. 80, § 57.

${ }^{30}$ ADORNO, 1993, p. 176, § 129.

${ }^{31}$ ADORNO, 1993, p. 130, § 97.

${ }^{32}$ ADORNO, 1993, p. 122, § 91.

${ }^{33}$ A esse respeito, é interessante a posição de Adorno defendida no texto Tempo livre, publicado no livro Palavras e sinais.

${ }^{34}$ ADORNO, 1993, p. 122, § 91.

${ }^{35}$ ADORNO, 1993, p. 122, § 91.

${ }^{36}$ ADORNO, 1993, p. 137, § 100. 


\section{Referências bibliográficas:}

ADORNO, Theodor W. "Anotações sobre Kafka". In: ADORNO, Theodor W. Prismas: crítica cultural e sociedade. Tradução de Augustin Wernet e Jorge Mattos Brito de Almeida. São Paulo: Ática, 2001.

. Minima moralia: reflexões a partir da vida danificada. Tradução de Luiz Eduardo Bica. 2. ed. São Paulo: Ática, 1993.

. Palavras e sinais: modelos críticos 2. Tradução: Maria Helena Ruschel.

Petrópolis: Vozes, 1995.

GEULEN, Eva. No happiness without fetishism. In: Feminist interpretations of Theodor Adorno. Edited by Renée Heberle. Pennsylvania: The Pennsylvania State University Press, 2006.

HEGEL, G. W. F. Fenomenologia do espírito. Tradução de Paulo Meneses, com a colaboração de Karl-Heinz Efken e José Nogueira Machado. 7. ed. Petrópolis: Vozes; Bragança Paulista: USF, 2002.

LEE, Lisa Yun. The Bared-Breasts Incident. In: Feminist interpretations of Theodor Adorno. Edited by Renée Heberle. Pennsylvania: The Pennsylvania State University Press, 2006. 